\title{
Numerical study of stress shielding evaluation of hip implant stems coated with composite (carbon/PEEK) and polymeric (PEEK) coating materials.
}

\author{
Ayham Darwich ${ }^{1,2 *}$, Hasan Nazha ${ }^{1,2}$, William Abbas ${ }^{3}$ \\ ${ }^{1}$ Department of Biomedical Engineering, Al-Andalus University for Medical Sciences, Tartous, Syria \\ ${ }^{2}$ Department of Technical Engineering, Tartous University, Tartous, Syria \\ ${ }^{3}$ Department of Mechanical Engineering, Czech Technical University, Prague, Czech Republic
}

\begin{abstract}
The forces applied to the prosthesis during human activity produce dynamic stresses varying in time and may causing stress shielding in prosthesis-bone system. Therefore, it is important to reduce stress shielding effect. This study aimed to investigates, using finite element analysis, how a PEEK and carbon/ PEEK composite coating materials on a titanium alloy hip implant stem could reduce stress shielding effect corresponding to different human activities: standing up, normal walking and climbing stairs under dynamic loadings to find out which of all these models have a better performance. A 3D finite element model of femur, hip implants, coating layers with composite (carbon/PEEK) and polymeric (PEEK) coating materials were constructed for finite element analysis. A time-dependent cycling load was applied on the prosthesis head. The maximum increase in load transfer to the bone was $207 \%$ for the prosthesis coated with carbon/PEEK configuration I (fibers orientated with $0,+45,-45$, and 90 degrees) in average compared to uncoated one. Numerical result showed that the carbon/PEEK composite material (configuration I) seems to be a good solution to distribute the applied load and transfer it to the bone, thus to reduce stress shielding problems and to prolong lifetime of the prosthesisbone system. It will prevent aseptic loosening and enhance the stability of the system.
\end{abstract}

Keywords: Hip prosthesis, Stress shielding, Finite element analysis, Coatings, PEEK, Carbon/PEEK. Accepted on February 4, 2019

\section{Introduction}

Total hip replacement (THR) technique is considered as the most useful treatment option for osteoarthritis and rheumatoid arthritis on the hip joint, enabling the patients to recover painfree mobility $[1,2]$. That is the reason THR attracted the interest of many specialists during the last decades. Hip implants are designed to last for 20 years at least, however stress shielding might be increased by several problems causing failure. The most important factors are conflicts in physical properties of the implant and the body, biocompatibility and surgical procedures. If the shape or material of a stem prompts to high stresses in fixation areas, stress shielding is quite probably to happen [3]. The loads applied to the prosthesis during human activity produce dynamic stresses varying in time and may causing stress shielding in the prosthesis-bone system; hence, it is important to reduce stress shielding effect.

The design of hip implant affects the osseointegration of implants [4]. Numerous techniques are utilized to achieve osseointegration including applying a coating layer that intends to obtain the effective osseointegration with a vital boneimplant contact [5]. It likewise enhances the stress distribution in the bone-prosthesis system, which would decrease stress shielding effect [6].

Advanced composites appear to be promising for implant applications on account of their high degree of biocompatibility with respect to strength and stiffness. The fiber orientation plays an important role in the mechanical behavior of the composite materials $[7,8]$. The change in fiber orientation incites a change in mechanical properties of the composite materials such as tensile strength, elastic and shears modulus [9].

Some research concentrates on the effect of stress shielding in total hip arthroplasty. Sanchez et al. [6] used finite element analysis to investigate the influence of polyether ether ketone (PEEK) coating on titanium alloy hip implant stress shielding under static loading. They found that PEEK coating can improve the hip implant durability because of enhanced load transfer to the bone and reduced stress-shielding effect. Castellini et al. [10] studied hydroxyapatite double-coated hip implant stems. They found that performing a hydroxyapatite double coating on the whole surface of the porous titanium alloyed to eliminate pointed contact and stress concentration on the distal cortical, and reduced the risk of thigh pain and stress- 
shielding effect. Utzscheider et al. [11] studied the carbon/ PEEK composites properties in mouse. It has been demonstrated that the properties of carbon/PEEK, specifically density, strength and Young's modulus are very close to these of the human bones. This is in agreement with what Scholz et al. [12] reported in their review of using the composite materials in modern orthopaedic medicine and prosthetic devices.

In literature, stress shielding effect in the system has been analysed for cemented prosthesis with hydroxyapatite (HA) material and coated prosthesis with PEEK material. However, it is noted in the literature that previous studies were limited to normal walking condition, and it was limited also to the materials previously mentioned. To our knowledge, this is the first investigation of the influence of PEEK and carbon/PEEK composite coating materials on titanium alloy hip implant stress shielding under dynamic loadings. Therefore, the aim of this study is to investigates, using 3D finite element method, how a PEEK and carbon/PEEK composite coating materials on a titanium alloy hip implant stem could reduce stress shielding effect corresponding to different human activities: standing up, normal walking and climbing stairs under dynamic loadings to find out which of all these models have a better performance in the prosthesis-bone systems.

\section{Materials and Methods}

\section{Model generation}

The standard "Sawbones" Pacific Research Labs Inc. model was utilized as a beginning stage for the femur [13]. This model was modified on SolidWorks ${ }^{\circledR}$ software to create a new geometry of the femur after the THR procedure. The hip implants was also developed using SolidWorks ${ }^{\circledR}$ software with a length of $140 \mathrm{~mm}$ as it shown in Figure 1. Stem and neck lengths are $100 \mathrm{~mm}$ and $48.7 \mathrm{~mm}$, respectively. The neck diameter and angle are $12 \mathrm{~mm}$ and $120^{\circ}$, respectively. The assembled geometry of the femur and implant is shown in Figure 2. All contacts interfaces between bone-coating layer, and coating layer-implant stem were modeled as a bonded contact type [6,8]. A frictional contact with a friction coefficient of 0.2 was considered for the bone-implant interface in the uncoated implementation [14]. Models of the femur, the $2 \mathrm{~mm}$ thick coating layer and the stem were exported to ANSYS and assembled into a single finite element (FE) model. Elements for FEA were tetrahedrons. Mesh size convergence rate has been investigated numerically, and the most suitable mesh for the study consisted of 99566 tetrahedral elements and 163757 nodes as shown in Figure 3 with 2 and $2.8 \mathrm{~mm}$ as the minimum and maximum element size, respectively.

\section{Boundary conditions}

Boundary conditions were defined to simulate dynamic loading conditions. A time-dependent cycling load was applied on the prosthesis head, where the distal end of the bone was fixed as shown in Figure 3. Time history of the dynamic load cycle components for 1.2 seconds is demonstrated in Figure 4 corresponding to different human activities: standing up, normal walking and climbing stairs as mentioned in Bergmann et al. [15], and the description of this activity are listed in Table 1.

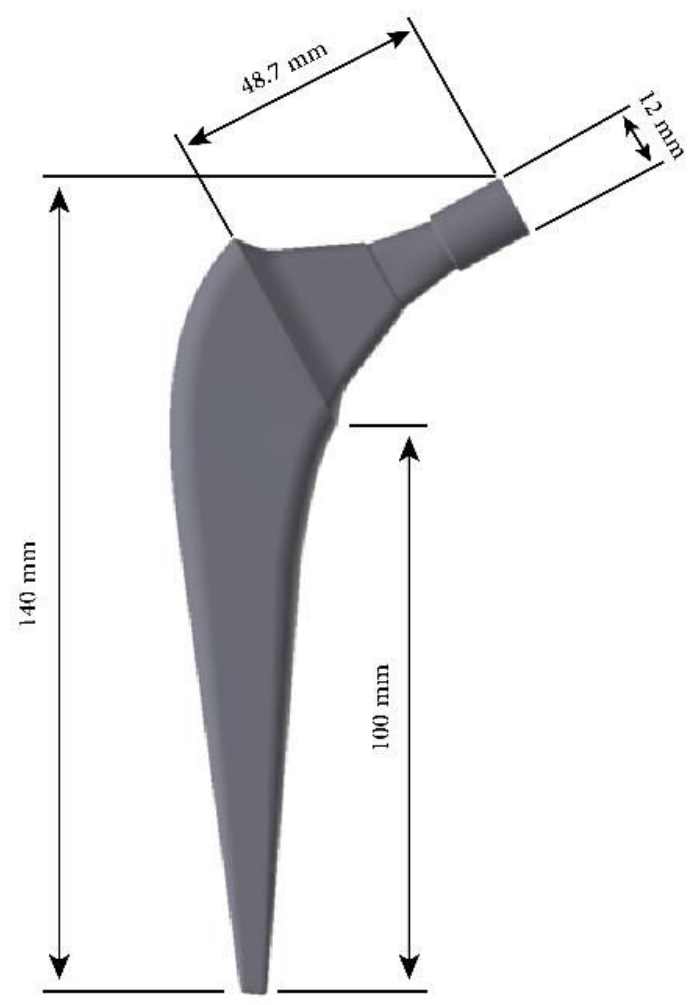

Figure 1. Dimensions of hip implant stem used in the current study.

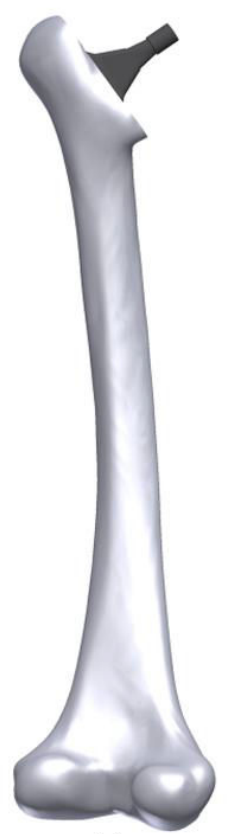

(a)

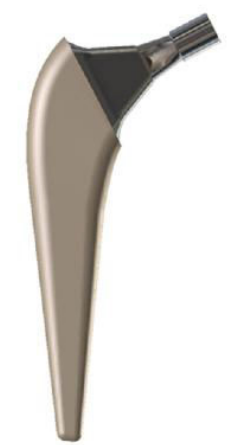

coated hip implant

(b)

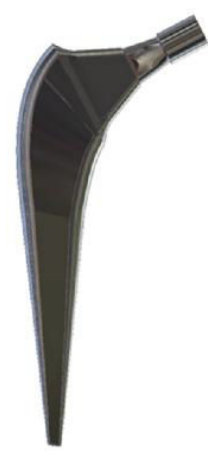

uncoated hip implant

(c)
Figure 2. CAD models: (a) the implanted femur model, (b) coated hip implant and (c) uncoated hip implant. 


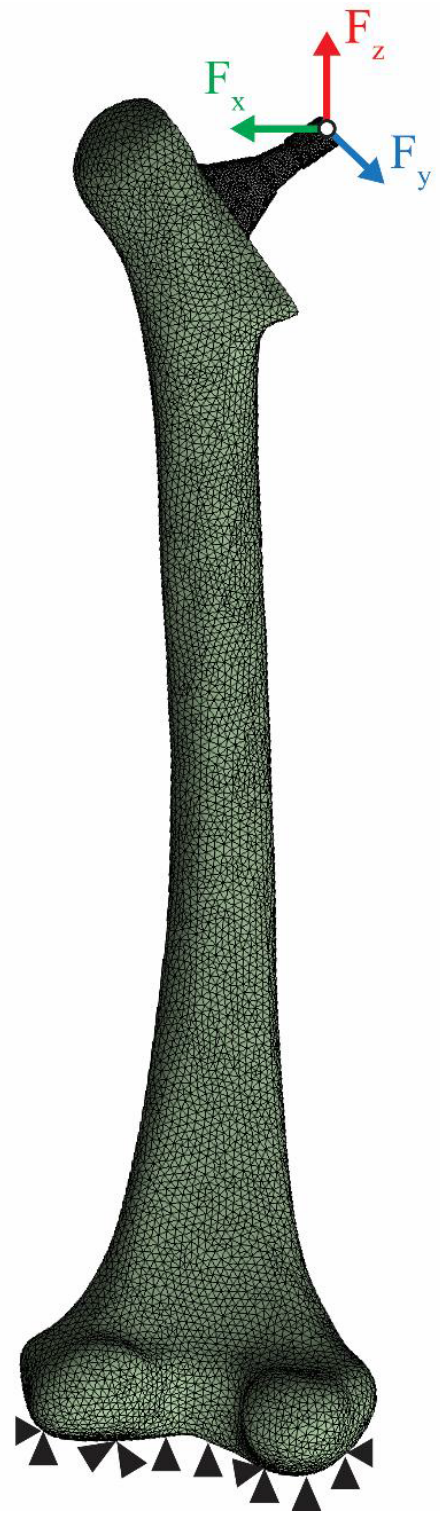

Figure 3. Boundary conditions and mesh of model.

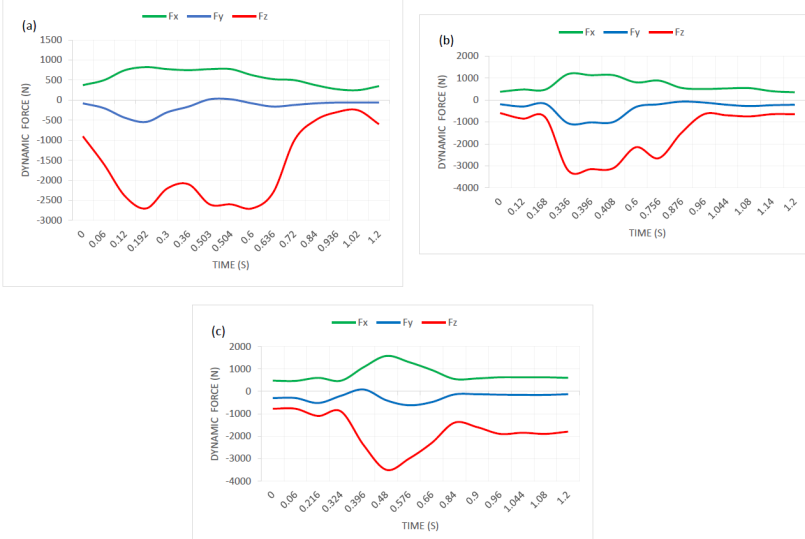

Figure 4. Time history of load components on the prosthesis: (a) normal walking, (b) stairs up, (c) standing up.
Femoral movements were restricted in all directions at the tibiofemoral joint surface and the coating interface (proximal and distal segments) was in contact but free to displace or separate. Table 2 describes the details of the studied patient in terms of his age, body weight, and anatomical specification.

\section{Material properties}

In the present study, the cortical bone was assumed as an orthotropic material while the cancellous bone was modelled as a linear isotropic material. The orthotropic materials do not have uniform mechanical properties in every direction [16]. While, isotropic materials have the same mechanical properties regardless of loading direction [17]. The elastic constants of the bone, Ti alloy prosthesis, and PEEK 150 XF coating are presented in Table 3 [6].

The properties of carbon/PEEK composite coating presented in Table 4 are based on two different configurations as shown in Figure $5[8,18]$. The fiber plies in configuration I are orientated multidirectional with fiber orientations of $0,+45,-45$, and 90 degrees, while the fiber plies in configuration II are orientated multidirectional and alternated with fiber orientations of -45 and +45 degrees. Equations 1-4 present the strength criteria of prosthesis components [19].

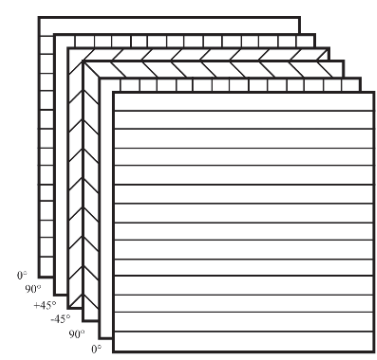

configuration I

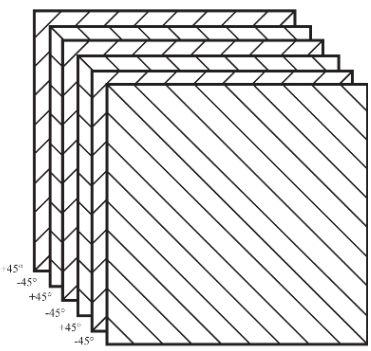

configuration II
Figure 5. Ply configurations for carbon/PEEK composites: (a) configuration I, (b) configuration II.

$\sigma_{\text {stem }} \leq\left(\sigma_{\text {yield }}=800 \mathrm{MPa}\right) \rightarrow(1)$

$\sigma_{\text {PEEK }}$ coating $\leq\left(\sigma_{\text {yield }}=102 \mathrm{MPa}\right) \rightarrow(2)$

$\sigma_{\text {configuration I coating }} \leq\left(\sigma_{\text {yield }}=627.5 \mathrm{MPa}\right) \rightarrow(3)$

$\sigma_{\text {configuration II coating }} \leq\left(\sigma_{\text {yield }}=327.4 \mathrm{MPa}\right) \rightarrow(4)$

\section{Results}

From the FE analysis, numerical results of maximum von Mises stress obtained for different hip implant stems were showed that $2 \mathrm{~mm}$ coating layer of PEEK or carbon/PEEK coating material have almost the same influence in decreasing maximum stress in hip implant stems in comparison with uncoated one. A maximal stress value of $278.76 \mathrm{MPa}$ has appeared in standing up conditions for uncoated stems, while the lowest value $78.74 \mathrm{MPa}$ was noted for coated stems in normal walking condition. All of maximum stress values obtained for different hip implant stems are lower than yielding stress of implant stems material that mentioned in Equation 1 $\left(\sigma_{\text {yield }}=800 \mathrm{MPa}\right)$ 


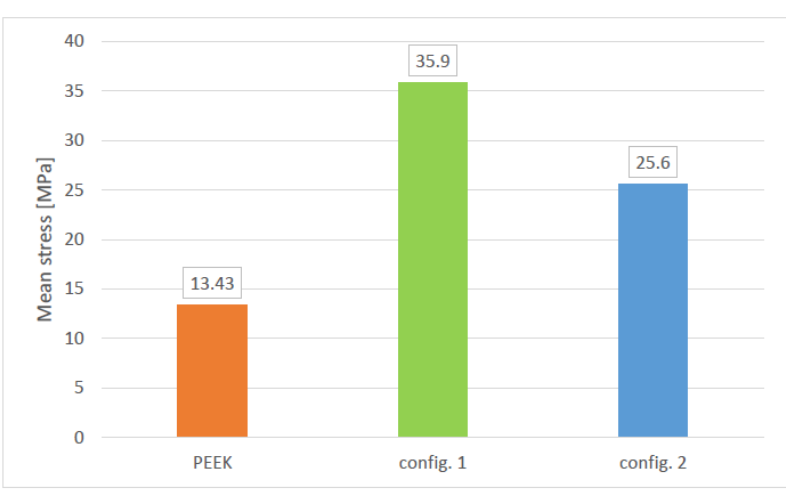

Figure 6. Mean stress values of different coating materials under dynamic conditions.

Table 1. Description of analysed activities.

\begin{tabular}{ll}
\hline Activity & Description \\
\hline $\begin{array}{l}\text { Normal } \\
\text { walking }\end{array}$ & Level walking, speed $=1.0-1.3 \mathrm{~m} / \mathrm{s}$; average $=1.1 \mathrm{~m} / \mathrm{s}$ \\
\hline Stairs up & Without use of handrail. Step height $=19.8 \mathrm{~cm}$, width $=26.3 \mathrm{~cm}$ \\
\hline Standing up & Without use of armrest. Seat height $=45 \mathrm{~cm}$ \\
\hline
\end{tabular}

Table 2. Personal data of patient.

\begin{tabular}{ll}
\hline Gender & Male \\
\hline Age (years) & 60 \\
\hline Operated joint & Right \\
\hline Body weight $(\mathrm{kg})$ & 75 \\
\hline
\end{tabular}

Table 3. Material properties of the bone, PEEK, and Ti alloy prosthesis.

\begin{tabular}{lllll}
\hline Material & Plane & $\begin{array}{l}\text { Elastic modulus } \\
(\mathrm{E})(\mathrm{GPa})\end{array}$ & $\begin{array}{l}\text { Shear modulus } \\
(\mathrm{G})(\mathrm{GPa})\end{array}$ & $\begin{array}{l}\text { Poisson's } \\
\text { ratio }\end{array}$ \\
\hline $\begin{array}{l}\text { Cortical } \\
\text { bone }\end{array}$ & $\mathrm{xx}$ & 11.5 & - & - \\
\cline { 2 - 5 } & $\mathrm{yy}$ & 11.5 & - & - \\
\cline { 2 - 5 } & $\mathrm{zz}$ & 17 & - & - \\
\hline & $\mathrm{xy}$ & - & 3.6 & 0.51 \\
\cline { 2 - 5 } & $\mathrm{yz}$ & - & 3.3 & 0.31 \\
\cline { 2 - 5 } & $\mathrm{xz}$ & - & 3.3 & 0.31 \\
\hline $\begin{array}{l}\text { Cancellous } \\
\text { bone }\end{array}$ & 2.13 & - & 0.3 \\
\hline Ti-6Al-4V & 114 & & 0.33 \\
\hline
\end{tabular}

To investigate which coating material have the best performance as a stem coating layer in the prosthesis-bone system, the FE analysis for maximum von Mises stress induced in coating layers was used, and the results have been tabulated in Table 5. We can see that configuration I coating layer is more stressed than other coating materials in the different conditions, which means that load transfer for configuration I coating layer were higher than others, and thus it will reduce stress shielding effect.

Table 4. Elasticity constants of carbon/PEEK composites.

\begin{tabular}{|c|c|c|c|c|c|}
\hline $\begin{array}{l}\text { Carbon/PEEK } \\
\text { composites } \\
\text { material }\end{array}$ & Plane & $\begin{array}{l}\text { Elastic } \\
\text { modulus } \\
(\mathrm{GPa})\end{array}$ & $E$ & $\begin{array}{l}\text { Shear modulus } \\
\text { (G) (GPa) }\end{array}$ & $\begin{array}{l}\text { Poisson's } \\
\text { ratio }\end{array}$ \\
\hline \multirow[t]{6}{*}{ Configuration I } & $x x$ & 4 & & - & - \\
\hline & yy & 9.8 & & - & - \\
\hline & $\mathrm{zz}$ & 9.8 & & - & - \\
\hline & xy & - & & 3.5 & 0.51 \\
\hline & $y z$ & - & & 3 & 0.31 \\
\hline & $x z$ & - & & 3.5 & 0.31 \\
\hline \multirow[t]{6}{*}{ Configuration II } & $x x$ & 4.5 & & - & 0.3 \\
\hline & yy & 15.5 & & - & 0.33 \\
\hline & $\mathrm{zz}$ & 15.5 & & - & - \\
\hline & $x y$ & - & & 4 & 0.3 \\
\hline & $y z$ & - & & 3.5 & 0.3 \\
\hline & $x z$ & - & & 4 & 0.3 \\
\hline
\end{tabular}

Table 5. Maximum von Mises stresses (in MPa) of the coating materials with various conditions.

\begin{tabular}{llll}
\hline Activity & PEEK & Configuration I & Configuration II \\
\hline Normal walking & 8.72 & 25.39 & 16.91 \\
\hline Climbing stairs & 15.39 & 41.78 & 29.79 \\
\hline
\end{tabular}

Table 6. Maximum von Mises stresses (in MPa) of the cancellous bone included different models and change of coated versus uncoated models (in \%) with various conditions.

\begin{tabular}{|c|c|c|c|c|}
\hline Coating condition & $\begin{array}{l}\text { Normal } \\
\text { walking }\end{array}$ & $\begin{array}{l}\text { Climbing } \\
\text { stairs }\end{array}$ & $\begin{array}{l}\text { Standing } \\
\text { up }\end{array}$ & Average \\
\hline Uncoated (Mpa) & 2.36 & 2.35 & 2.42 & 2.38 \\
\hline Coated with PEEK (Mpa) & 4.61 & 8.45 & 7.83 & 6.96 \\
\hline $\begin{array}{l}\text { Change coated versus uncoated } \\
(\%)\end{array}$ & $95 \%$ & $259 \%$ & $223 \%$ & $192 \%$ \\
\hline $\begin{array}{l}\text { Coated with configuration I } \\
\text { (MPa) }\end{array}$ & 4.82 & 8.45 & 8.68 & 7.32 \\
\hline $\begin{array}{l}\text { Change coated versus uncoated } \\
(\%)\end{array}$ & $104 \%$ & $259 \%$ & $258 \%$ & $207 \%$ \\
\hline $\begin{array}{l}\text { Coated with configuration II } \\
\text { (MPa) }\end{array}$ & 4.62 & 8.49 & 8.46 & 7.19 \\
\hline $\begin{array}{l}\text { Change coated versus uncoated } \\
(\%)\end{array}$ & $95 \%$ & $261 \%$ & $249 \%$ & $202 \%$ \\
\hline
\end{tabular}

The calculated stresses are much lower than the yielding stresses of prosthesis components given in Equations 1-4. This means, prosthesis with different component materials are safe 


\section{Numerical study of stress shielding evaluation of hip implant stems coated with PEEK and carbon/PEEK coating materials}

whatever the activity: normal walking, climbing stairs or standing up.

Figure 6 shows comparison of stress values for different coating materials averaged across dynamic case. In comparison of carbon/PEEK configuration I versus other coating materials, it could be observed that mean stress value is higher than others, where the stress value for configuration I (35.9 MPa) is high compared to PEEK (13.43 $\mathrm{MPa})$ and compared to configuration II (25.6 MPa).

The analysis results shown in Table 6 are based on the cancellous bone stress. It is shown that the minimum increase in load transfer to the bone is $192 \%$ for the prosthesis coated with PEEK in average compared to uncoated one, while the maximum increase is $207 \%$ for the prosthesis coated with configuration I in average compared to uncoated one.

This increment in load transferred to the bone can influence mineral bone loss due to stress shielding, minimizing such effect, and thus prolonging prosthesis component lifespan.

\section{Discussion}

In this study, 3D finite element analysis was used to assess the performances of models, and to understand the influence of different daily activities such as standing up, normal walking and climbing stairs on stress distribution in the prosthesis-bone system. The proposed approach would open the possibility to enhance hip prosthesis performance without the need to develop implant geometry. Consequently, any available implant could be treated by choosing a proper coating process, and its performance can be enhanced. The results showed a decrease of $4.6 \%$ at least in induced stress for the coated prosthesis compared with uncoated one. The decreasing of induced stress achieved by the increment in load transferred to the bone via coating layer, which minimizing stress-shielding effect. From Table 5, configuration I composite coating layer shows an increase of $20.2 \%, 28.7 \%$ and $25.77 \%$ at least in transmitted stress under normal walking, climbing stairs and standing up condition respectively compared with other coating materials. From Table 6, hip implant stems coated with configuration I composite coating layer shows a maximum increase of $207 \%$ at least in mean transmitted stress to the cancellous bone compared to uncoated one. This was achieved by the ability of the configuration I coating layer to distribute the stresses throughout the prosthesis-bone system. As previously mentioned, two different composite fiber configurations were used to address the biomechanical behavior of carbon/PEEK composite coated prosthesis. The fiber plies in configuration I are orientated multidirectional with fiber orientations of $0,+45,-45$, and 90 degrees, while the fiber plies in configuration II are orientated multidirectional and alternated with fiber orientations of -45 and +45 degrees. It is known that the fiber orientation plays a very important role in the mechanical behavior of the composite materials [8]. In configuration I, as the fibers orientated with $0,+45,-45$, and 90 degrees, the distribution of the applied load was the best due to this orientation of fibers that achieve the homogenous mechanical behavior in the system. This material enable to distribute the applied load and transfer it to the bone, that can influence mineral bone loss due to stress-shielding, minimizing stress-shielding effect, and thus it will be safer and more durable compared to the other models. No earlier studies have examined how a PEEK and carbon/PEEK composite coating materials on a titanium alloy hip implant stem could reduce stress shielding effect corresponding to different human activities: standing up, normal walking and climbing stairs under dynamic loadings. However, comparison of current results to prior studies on primary hip prosthesis may be instructive. Sanchez et al. [6], Enab [20] and Fouda [21], showed that PEEK and composite coatings led to reduce the stress in coated hip implants, and thus prolong its lifespan due to enhanced load transfer to the bone and minimized stress shielding effect which was in agreement with the presented results in this study. Based on the results in this study, uncoated prosthesis was not good and led to bad performance. On the contrary, the coated prosthesis showed good performance, where the results showed that the use of configuration I coating material predicted to be a good solution to distribute the applied load and transfer it to the bone, thus to reduce stress shielding problems and to prolong lifetime of the prosthesisbone system. It will prevent aseptic loosening and enhance the stability of the prosthesis. This is due to the decrease in the mismatching between the stiffness of the coated prosthesis (configuration I) with the bone.

A few limitations remain in the current study and must be considered in the model in order to optimize computational resources without influencing essential analysis. Given that the proposed design concept depends on press-fit type implants, a porous surface should be considered. The finite element model mimicked long-term bone ingrowth around the stem by employing contact conditions at all implant-bone, implantcoating, and bone-coating interfaces, i.e., bone absorption/ apposition was disregarded. Nevertheless, ongoing bone remodeling over the lifespan of the implant will alter implantfemur biomechanics.

Given the limitations of extrapolating results to clinical practice and the fact that it is difficult to reproduce anatomical and physiological conditions exactly in FEA, the present results should be treated with caution. The use of model with carbon/PEEK composite configuration I coating material seem to present a better performance in the femur, so it could efficiently reduce the stress shielding and thus prolonging the system lifespan.

\section{Conclusion}

This study aimed to investigates how a PEEK and carbon/ PEEK composite coating materials on a titanium alloy hip implant stem could reduce stress shielding effect corresponding to different human activities: standing up, normal walking and climbing stairs under dynamic loadings to find out which of all these models have a better performance. 
This work demonstrates that the coated prosthesis showed good performance, where the results showed that the use of configuration I coating material predicted to be a good solution to distribute the applied load and transfer it to the bone, thus to reduce stress shielding problems and to prolong lifetime of the prosthesis-bone system. It will prevent aseptic loosening and enhance the stability of the prosthesis. This is due to the decrease in the mismatching between the stiffness of the coated prosthesis (configuration I) with the bone.

\section{Acknowledgment}

This research did not receive any specific grant from funding agencies in the public, commercial, or not-for-profit sectors.

\section{References}

1. Holzwarth U, Cotogno G. Total hip arthroplasty: state of the art, challenges and prospects-European commission. Joint Research Centre 2012.

2. de Almeida DF, Ruben RB, Folgado J, Fernandes PR, Gamelas J, Verhegghe B, De Beule M. Automated femoral landmark extraction for optimal prosthesis placement in total hip arthroplasty. Int J Numeric Meth Biomed Eng 2017; 33: e2844.

3. Hernandez-Rodriguez MAL, Ortega-Saenz JA, ContrerasHernandez GR. Failure analysis of a total hip prosthesis implanted in active patient. J Mech Behav Biomed Mater 2010; 8: 619-622.

4. Khanuja HS, Vakil JJ, Goddard MS, Mont MA. Cementless femoral fixation in total hip arthroplasty. J Bone Joint Surg Am 2011; 93: 500-509.

5. Branemark PI, Zarb G, Albrektsson T. Tissue-integrated prostheses: osseointegration in clinical dentistry. J Prosth Dent 1985; 54: 611-612.

6. Anguiano-Sanchez J, Martinez-Romero O, Siller HR, Diaz-Elizondo JA, Flores-Villalba E, Rodriguez CA. Influence of PEEK coating on hip implant stress shielding: a finite element analysis. Comp Math Meth Med 2016; 6183679.

7. Yong CK, Ching YC, Chuah CH, Liou NS. Effect of fiber orientation on mechanical properties of kenaf-reinforced polymer composite. BioResources 2015; 10: 2597-2608.

8. Rezaei F, Hassani K, Solhjoei N, Karimi A. Carbon/PEEK composite materials as an alternative for stainless steel/ titanium hip prosthesis: a finite element study. Aus Phys Eng Sci Med 2015; 38: 569-580.

9. Liang J, Kalyanasundaram S. Effect of fiber orientation on the failure behavior of a glass-fiber reinforced thermoplastic composite. AIP Conference Proc 2017; 1846: 020003.

10. Castellini I, Andreani L, Parchi PD, Bonicoli E, Piolanti N, Risoli F, Lisanti M. Hydroxyapatite in total hip arthroplasty. Our experience with a plasma spray porous titanium alloy/hydroxyapatite double-coated cementless stem. Clin Cases Mineral Bone Metabol 2016; 13: 221.
11. Utzschneider S, Becker F, Grupp TM, Sievers B, Paulus A, Gottschalk O, Jansson V. Inflammatory response against different carbon fiber-reinforced PEEK wear particles compared with UHMWPE in vivo. Acta Biomater 2010; 6: 4296-4304.

12. Scholz M, Blanchfield JP, Bloom LD, Coburn B, Elkington M, Fuller J, Gilbert M, Muflahi S, Pernice M, Rae SI, Trevarthen J, White S, Weaver P, Bond I. The use of composite materials in modern orthopaedic medicine and prosthetic devices: a review. Compos Sci Technol 2011; 71: 1791-1803.

13. Chang PB, Williams BJ, Bhalla KS, Belknap TW, Santner TJ, Notz WI, Bartel DL. Design and analysis of robust total joint replacements: finite element model experiments with environmental variables. J Biomech Eng 2001; 123: 239-246.

14. Caouette C, Yahia LH, Bureau MN. Reduced stress shielding with limited micromotions using a carbon fibre composite biomimetic hip stem: a finite element model. J Eng Med 2011; 225: 907-919.

15. Bergmann G, Bender A, Dymke J, Duda G, Damm P. Standardized loads acting in hip implants. PLoS One 2016; 11: e0155612.

16. Elhamian SMM, Alizadeh M, Shokrieh MM, Karimi A. A depth dependent transversely isotropic micromechanic model of articular cartilage. J Mater Sci Mater Med 2015; 26: 1-10.

17. Shahmohammadi M, Shirazi HA, Karimi A, Navidbakhsh M. Finite element simulation of an artificial intervertebral disk using fiber reinforced laminated composite model. Tissue Cell 2014; 46: 299-303.

18. Williams PL, Warwick R, Dyson M, Bannister LH. Grays anatomy (37th Edn.). Churchill Livingstone 1989; 661-858.

19. Kayabasi O, Ekici B. The effect of static, dynamic and fatigue behavior on three-dimensional shape optimization of hip prosthesis by finite element method. Mater Design 2007; 28: 2269-2277.

20. Enab T. Behavior of FGM-coated, HA-coated and uncoated femoral prostheses with different geometrical configurations. Int J Mech Mechatron Eng 2016; 16: 62-71.

21. Fouda N. Horizontal functionally graded material coating of cementless hip prosthesis. Trends Biomater Artificial Organs 2014; 28: 58-64.

\section{*Correspondence to}

Ayham Darwich

Department of Biomedical Engineering

Al-Andalus University for Medical Sciences

Syria 